\begin{tabular}{|c|}
\hline 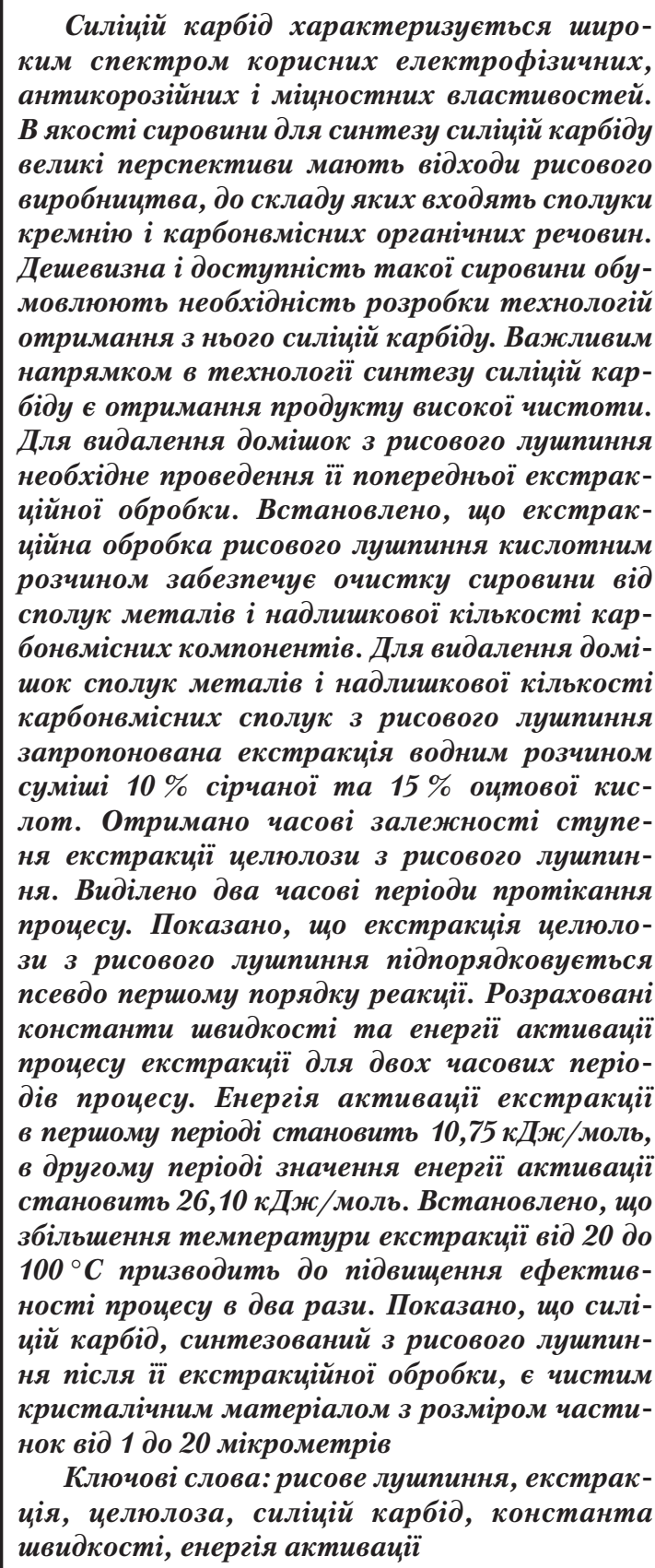 \\
\hline
\end{tabular}

UDC $661.665 .1+663.584 .6$

DOI: $10.15587 / 1729-4061.2020 .195881$

\section{STUDYING THE KINETICS OF EXTRACTION TREATMENT OF RICE HUSK WHEN OBTAINING SILICON CARBIDE}

\author{
A. Liashenko \\ Assistant*
}

E-mail: liashenkoanya@gmail.com

Y. S k n a r

Doctor of Chemical Sciences, Professor*

E-mail: yuriy.sknar@gmail.com

T. H r y d n i e a

$\mathrm{PhD}$, Senior Lecturer*

E-mail: tasya.gridneva@gmail.com

P. R i a b i k

PhD, Associate Professor*

E-mail: pavelriabik@gmail.com

O. De m c h y s h y n a

$\mathrm{PhD}$, Assistant

Department of Mineral Processing and Chemistry

Kryvyi Rih National University

Vitaliya Matusevycha str., 11, Kryvyi Rih, Ukraine, 50027

E-mail: demchyshynaov@gmail.com

$K$. PIy a sovskaya

$\mathrm{PhD}$, Associate Professor

Department of Physical and Inorganic Chemistry

Oles Honchar Dnipro National University

Gagarina ave., 72, Dnipro, Ukraine, 49010

E-mail: pea1975@list.ru

*Department of Processes, Apparatus and General Chemical Technology

Ukrainian State University of Chemical Technology

Gagarina ave., 8, Dnipro, Ukraine, 49005

\section{Introduction}

Silicon carbide is one of the most important materials that has been widely used in various industries. This material is characterized by a set of useful strength, electrophysical, and anti-corrosion properties. The hardness of silicon carbide is second only to the hardness of diamond, which predetermined its use as an abrasive material. Given its high thermal conductivity, $\mathrm{SiC}$ is a valuable material for the manufacture of bearings. Of practical interest is the silicon-carbide-based ceramics, which has both heat resistance and high chemical stability. Along with a conventional use in the abrasive, fire-resistant, and metallurgical industries, it is increasingly used in electrical engineering, the space sector, and nuclear power generation. Silicon carbide has semiconductor properties. This makes it possible to use it as a wide-zone semiconductor for high-temperature high-power electronic devices. The operational stability and reliability of semiconductor devices made on its basis are maintained at temperatures of up to $600{ }^{\circ} \mathrm{C}$. The high width of the exclusion zone and high thermal conductivity make it possible to obtain devices based on silicon carbide, which can work under extreme conditions - at elevated temperatures and under the influence of radiation [1]. In the optoelectronic industry, silicon carbide 
is used to fabricate LEDs, photodiodes, as well as optical units for terrestrial and space-based telescopes [2]. Silicon carbide is used to make solar cells, to create mirror elements in optical systems, in nuclear power generation.

In [3], it is proposed to use silicon carbide to produce temperature and magnetic field sensors. Work [4] reported a study of the optical properties of SiC obtained by implanting carbon to silicon. The authors established, for the resulting material, the dependences of the refraction index and the extinction coefficient on the energy of photons. It is concluded that the surface has enhanced roughness and there are defects in the crystal lattice of the material synthesized by a given method. The authors of [5] showed that the optoelectronic properties of silicon carbide can be improved by the introduction of intermediate states into the prohibited zone. Implementation of a given effect implies the supplementing of the structure of the crystal with transitional metals of group VIII from the periodic system. This opens a larger number of channels of photon absorption, thereby increasing the absorption of sunlight by solar cells.

Powdered SiC can be used for the manufacture of nonlinear semiconductor resistors, high-temperature heaters, wave absorbers. The scope of silicon carbide application is constantly expanding and is finding completely new uses. For example, in the environmental protection, when creating filters to purify gases from the diesel engines [6], in nanotechnology in the manufacture of injectors for the submicrospraying of fuel mixtures [7].

In recent years, the scientific field has been actively developing that studies the biological compatibility of silicon carbide and its application in medicine [8]. Thus, this material can be used in the creation of frames of bone implants, neurological implants and sensors, glucose sensors. Silicon carbide is proposed in [9] to be used as a material for osteosynthesis and the elimination of facial skull bone defects. It is obtained by impregnating with liquid silicon a carbon frame derived from pyrolysis from wood, in which the cell morphology of the tree is preserved.

Modern silicon carbide technologies are largely based on the Acheson method. The method implies conducting solid-phase chemical reactions at high temperatures $\left(1,400-2,500^{\circ} \mathrm{C}\right)[10]$. The crystalline product, the color of which can vary from light green to black, is obtained in electric resistance furnaces from purified quartz sand and oil coke. To obtain fine powders, the synthesized products are additionally subjected to prolonged grinding. This method excludes the possibility of obtaining material of increased purity.

A promising direction in the field of high purity silicon carbide synthesis is the processing of rice husks [11]. This raw material contains up to $23 \%$ (by weight) of silicon dioxide and up to $36 \%$ (by weight) of carbon in the form of the main organic ingredients - cellulose and lignin. Preliminary chemical cleaning of this raw material seems appropriate before the electrothermal treatment.

In this regard, it is a relevant, technologically, and economically sound task to study the kinetics of extraction processing of rice husks in obtaining silicon carbide.

\section{Literature review and problem statement}

The synthesis of silicon carbide, along with the traditional Acheson method, is carried out from gas-like raw materials using silanes and other organic compounds. This synthesis makes it possible to obtain high-purity silicon carbide, but the cost of products increases significantly $[12,13]$. High-temperature synthesis, plasma chemical methods, and ash-gel method are used to produce silicon carbide nanopowders [14].

The most economically feasible way to synthesize silicon carbide is to receive it from rice husks. The use of rice waste as a raw material for such synthesis reduces the cost of production. Work [15] reports the synthesis of silicon carbide during rice husk pyrolysis at $1,400{ }^{\circ} \mathrm{C}$ in an inert environment. In order to increase the output of the product, it is proposed to carry out the pre-treatment of raw materials with sodium silicate [16]. The authors of [11] obtained silicon carbide by the carbothermic restoration of rice husks. The raw materials were charred in a combustion furnace. The carbonized rice husks were crushed and then treated with hydrochloric acid of varying concentrations. That allowed the removal of metal compounds from the raw materials. The resulting powders were mixed with metallic silicon powder and exposed to pyrolysis at different temperatures in the atmosphere of argon or nitrogen.

The proposed methods of synthesis of silicon carbide from rice husks do not provide a product free of impurities. This is due to the presence of excess carbon in the raw material relative to silicon. Extracting organic components from the rice husk can be used to reduce the carbon content of rice husks.

Obtaining cellulose by extracting it from the rice husk using sulphuric acid is described in [17]. Thermogravimetric analysis was used to investigate the thermostability of rice husk fibers and the cellulose nanocrystals obtained. Paper [18] reports the environmentally friendly process of separating cellulose from rice husks. The multi-stage process involves the extraction of lignin through alkaline treatment and further delignification with a mixture of acetic and nitric acids. The proposed method of extraction processing of rice husks is promising for producing cellulose with high purity and crystallinity. Work [19] reported a two-stage chemical method of extracting microparticles of cellulose from rice husks. The authors of [20] note the high physical and chemical properties of cellulose fibers derived from rice husks by extraction. The process of alkaline extraction followed by acid deposition of pure silicon dioxide with minimal mineral contamination was considered in [21]. X-rays revealed the amorphous structure of the resulting silicon dioxide.

As shown by our review of the scientific literature, carrying out pyrolysis without first preparing raw materials leads to the contamination of silicon dioxide with carbon. The presence of compounds of various metals in the rice husk also requires the organization of the pre-cleaning of raw materials. At the same time, there are ways of the extraction treatment of rice husk aimed at obtaining valuable organic products. In this regard, it is important to study the patterns of extraction processing of rice husks in obtaining silicon carbide.

\section{The aim and objectives of the study}

The aim of this study is to establish patterns in the process of extraction treatment of rice husks to ensure a predetermined ratio of silicon and carbon in the pyrolysis synthesis of silicon carbide. This would provide an opportunity to improve the technology of obtaining silicon carbide from plant raw materials as regards its regulated cleaning of carbon-containing compounds. 
To accomplish the aim, the following tasks have been set:

- to investigate the effect of temperature on the time dependence of cellulose extraction degree and to assess the effectiveness of cleaning rice husks from impurities of metal compounds and carbon compounds when using an acid extractant;

- to determine values for the constants of speed and activation energy of the extraction treatment of rice husks depending on the time interval of the process.

\section{Materials and methods to study the extraction treatment of rice husk}

In the current work, we used rice husks whose mean composition is given in Table 1. To reduce the carbon content of rice husks, cellulose was extracted before pyrolysis.

Table 1

Mean composition of rice husk [22]

\begin{tabular}{|c|c|}
\hline Substance & Content, \% by weight \\
\hline Water & $2.4-11.35$ \\
\hline Protein & $1.7-7.26$ \\
\hline Fat & $0.38-2.98$ \\
\hline Ash & $13.6-29.04$ \\
\hline Cellulose & $51.28-65.8$ \\
\hline Lignin & $21.4-46.97$ \\
\hline
\end{tabular}

The empirical formula of cellulose is $\left(\mathrm{C}_{6} \mathrm{H}_{10} \mathrm{O}_{5}\right)_{n}$. When cellulose is treated with concentrated acids, the formation of jelly-like sediment is observed, which is difficult to separate from the insoluble part of the rice husk [23]. Therefore, the diluted aqueous solutions of sulphuric acid were used in our study. Acetic acid was used as an additive to produce a porous carbon structure. Fig. 1 shows that increasing the concentration of acetic acid in the extractant leads to a decrease in the time to achieve the maximum degree of extraction.

This effect is observed when the concentration of acetic acid changes from 5 to $15 \%$ (by weight). Further increase in the content of acetic acid in the extractant has almost no effect on the course of the time dependence. Based on the data obtained, a solution containing $10 \%$ (by weight) of sulphuric acid and $15 \%$ (by weight) of acetic acid was used as an extractant.

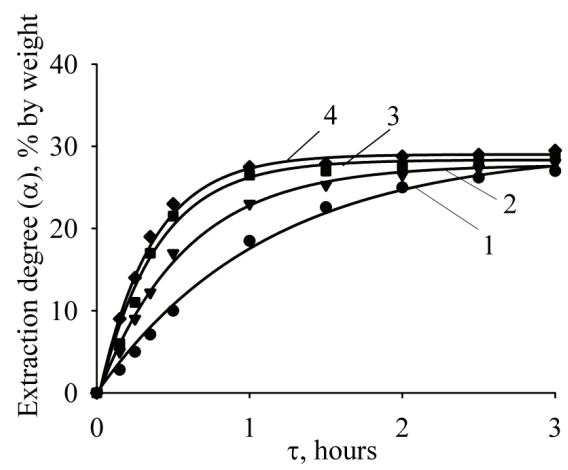

Fig. 1. Time dependence of the degree of extraction of cellulose from rice husk at $100^{\circ} \mathrm{C}$ with a solution containing $10 \%$ (by weight) of sulphuric acid and variable concentration of acetic acid, \% (by weight):

$$
1-5 ; 2-10 ; 3-15 ; 4-20
$$

We studied the process of extraction of cellulose from rice husks at a laboratory installation shown in Fig. 2.

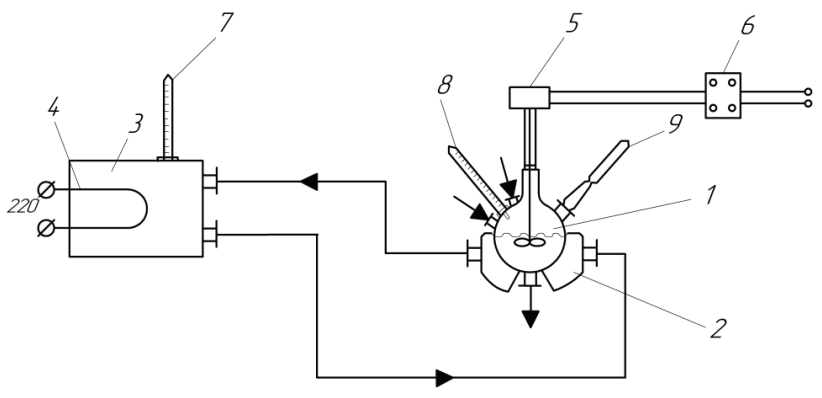

Fig. 2. Schematic of the laboratory installation to study the extraction process: 1 - reactor; 2 - thermostatically controlled jacket; 3 - thermostat; 4 - heating element; 5 - electric drive of the mixing device; 6 - transformer; 7 - pin thermometer; 8 - alcohol thermometer; 9 - water refrigerator

A sample of crushed rice husk weighing 5 grams was placed in thermostatically controlled reactor $1.50 \mathrm{ml}$ of the extractant was also poured there. The temperature of the extraction process was maintained in the range of 20 to $100^{\circ} \mathrm{C}$. The reactor was thermostatically controlled by circulating hot water through reactor jacket 2 . Water was pumped by the pump of thermostat 3 . The predefined temperature values were maintained by contact thermometer 7 installed in the thermostat. The reaction mixture was intensively stirred with propeller mixer 5 . The mixing device was powered by an electric drive. The duration of the process varied from 0.25 to 3 hours.

When studying the kinetics of cellulose extraction from rice husks, at the end of the experiment, the insoluble residue was filtered through a Schott glass filter under a vacuum using a waterjet pump. The rinsed sediment was dried at a temperature of $90-95^{\circ} \mathrm{C}$ in the air environment to a constant mass.

The degree of extraction was calculated according to formula:

$$
\alpha=\frac{G_{i}-G_{f}}{G_{f}},
$$

where $G_{i}$ and $G_{f}$ are the initial and final mass of the experimental sample, $g$.

The values of $\alpha$, derived from equation (1), are the average quantities, whose calculation involved experimental data from five identical experiments. The standard deviation of the values of a did not exceed 0.05.

Samples of rice husks after extraction, used to synthesize silicon carbide, were obtained by filtering the sediment through a paper «blue tape» filter. The sediment, taken to a magnesite-chromite crucible, was exposed to pyrolysis in the argon atmosphere at the MF- $1700 \mathrm{M}$ muffle furnace (Russia) at $1,500{ }^{\circ} \mathrm{C}$ for 2 hours.

The X-ray pictures of silicon carbide were acquired form the diffractometer DRON 3.0 (Russia) at $\mathrm{Cu}_{\mathrm{K} \alpha}$-radiation. The inter-plane distances on the X-ray pictures of the samples were compared with data from the ASTM library (American Society for Testing and Materials).

We studied the surface morphology of rice husk samples and its elemental composition using the REMMA 102-02 (Ukraine) raster electron microscope with an energy dispersion X-ray spectrometer. The measurement error did not exceed $0.15 \%$. 
The bulk density of silicon carbide was defined as the ratio of the weight of the batch to the volume it occupied. The mass of a silicon carbide batch was determined by the difference between the results of weighing a measuring cylinder of $25 \mathrm{~cm}^{3}$ with a silicon carbide batch and an empty cylinder. The volume of powder in the cylinder was determined after it was sealed at an oscillation amplitude of $40 \mathrm{~mm}$ and a frequency of oscillations of $100 \mathrm{~min}^{-1}$ for 10 minutes.

\section{Results of studying the extraction process patterns}

5. 1. Time dependences of cellulose extraction degree and the evaluation of the effectiveness of cleaning rice husks from impurities of metal compounds and carbon compounds

In the heat treatment of rice husks in the atmosphere of inert gases at a temperature of $1,300-1,500{ }^{\circ} \mathrm{C}$, silicon carbide is formed according to the chemical reaction equation:

$$
\mathrm{SiO}_{2}+3 \mathrm{C}=\mathrm{SiC}+2 \mathrm{CO}
$$

Rice husks contain silicon and carbon-containing components such as lignin and cellulose. The carbon content in the starting raw material exceeds the stoichiometric amount required for the progress of reaction (2). Excess carbon can be removed by extracting organic components. Moreover, this process can be carried out in a controlled manner and extract a strictly specified number of carbon-containing components. The extraction of cellulose with acidic solutions, compared to lignin, proceeds at a higher rate. Therefore, it can be considered that the regulation of carbon content in rice husks by acid extraction is carried out by extracting the predefined amount of cellulose.

Energy dispersion analysis of the elemental composition of rice husk (Table 2) indicates the presence of metal compounds such as iron, barium, calcium, potassium, manganese, aluminum in the sample.

Table 2

The content of elements in the starting rice husk and the husk after extraction treatment, $\%$ by weight

\begin{tabular}{|c|c|c|}
\hline Element & starting risk husk & husk after treatment \\
\hline $\mathrm{C}$ & 35.51 & 25.52 \\
\hline $\mathrm{O}$ & 47.54 & 55.93 \\
\hline $\mathrm{N}$ & 0.31 & 0.28 \\
\hline $\mathrm{Si}$ & 12.31 & 18.26 \\
\hline $\mathrm{Fe}$ & 2.54 & 0.000 \\
\hline $\mathrm{Ba}$ & 0.52 & 0.005 \\
\hline $\mathrm{Ca}$ & 0.31 & 0.005 \\
\hline $\mathrm{Mn}$ & 0.25 & 0.000 \\
\hline $\mathrm{K}$ & 0.37 & 0.000 \\
\hline $\mathrm{Al}$ & 0.34 & 0.000 \\
\hline
\end{tabular}

Following the extraction treatment, metal content in rice husks is negligible. Thus, the acid extraction of rice husks ensures its purification from impurities of metal compounds, thereby increasing the purity of starting raw materials to produce silicon carbide.

Time dependences of the degree of cellulose extraction from rice husks are shown in Fig. 3. An intensive change in the degree of extraction occurs over the initial 30 minutes of the process. The rate of extraction subsequently slows down. As the temperature of the process increases, the degree of extraction increases. Moreover, the character of dependences of the degree of extraction is maintained regardless of the temperature of the process. Thus, the resulting experimental dependences can be divided into two sections. The first section corresponds to the time of the process from 0 to 0.5 hours. The second section of the curves corresponds to the time of the process of $0.5-3$ hours.

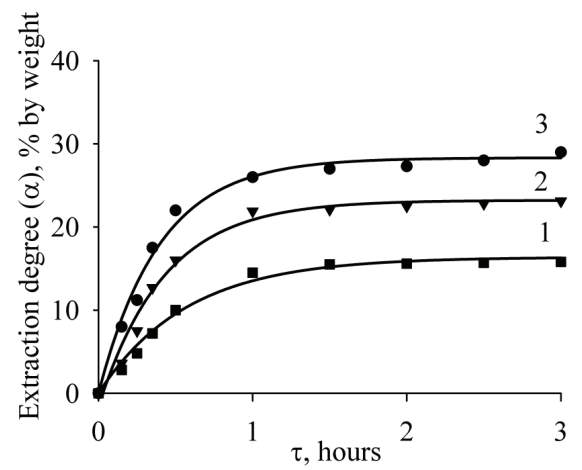

Fig. 3. Time dependence of the degree of cellulose extraction from rice husks at temperature, ${ }^{\circ} \mathrm{C}$ : $1-20 ; 2-40 ; 3-100$

The increase in the temperature of the extraction process leads to its acceleration and increases the degree of extraction. At the same extraction time, a temperature change from 20 to $100{ }^{\circ} \mathrm{C}$ causes a nearly doubling of the degree of cellulose extraction. This may be due to the intensification of hydrolysis destruction of glucoside and acetal bonds in cellulose, providing its fuller extraction from rice husks.

Based on the data on the kinetics of cellulose extraction from rice husks, it is advisable to calculate the corresponding changes in the $\mathrm{SiO}_{2}: \mathrm{C}$ ratio depending on the time and temperature of extraction. Fig. 4 shows that the $\mathrm{SiO}_{2}$ :C stochiometric ratio, equal to $1: 3$, is achieved at extraction at $100^{\circ} \mathrm{C}$. At lower extraction temperatures, the amount of carbon in the extractant-treated rice husk is excessive.

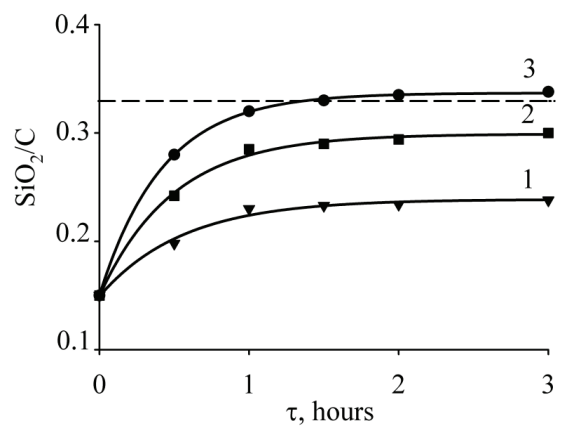

Fig. 4. Dependence of the $\mathrm{SiO}_{2}: \mathrm{C}$ ratio in rice husks on the time of extraction treatment at temperature, ${ }^{\circ} \mathrm{C}$ :

$$
1-20 ; 2-40 ; 3-100
$$

After extracting cellulose from rice husks over 3 hours at a temperature of $100{ }^{\circ} \mathrm{C}$, pyrolysis of the prepared raw materials was carried out. The resulting product was subjected to X-ray examination. Fig. 5 shows the product of rice husk pyrolysis after extraction treatment is silicon carbide. 
The clearly expressed peaks, observed on the X-ray picture, indicate the crystalline shape of the resulting silicon carbide. The blurred halo of the X-ray amorphous phase appears to correspond to the amorphous silicon dioxide that does not react with carbon. The presence of silicon dioxide may be due to a slightly inflated $\mathrm{SiO}_{2}$ : C ratio in the rice husks, used for the silicon carbide synthesis, treated with the extractant.

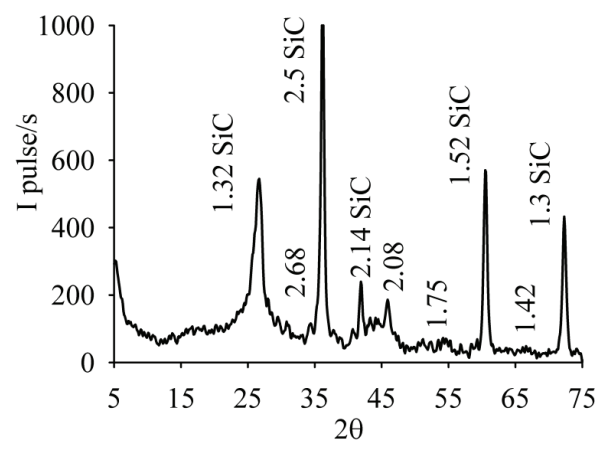

Fig. 5. X-ray picture of rice husk pyrolysis products after extraction treatment

A micro-photograph shown in Fig. 6 was acquired to estimate the size of the silicon carbide powder particles.

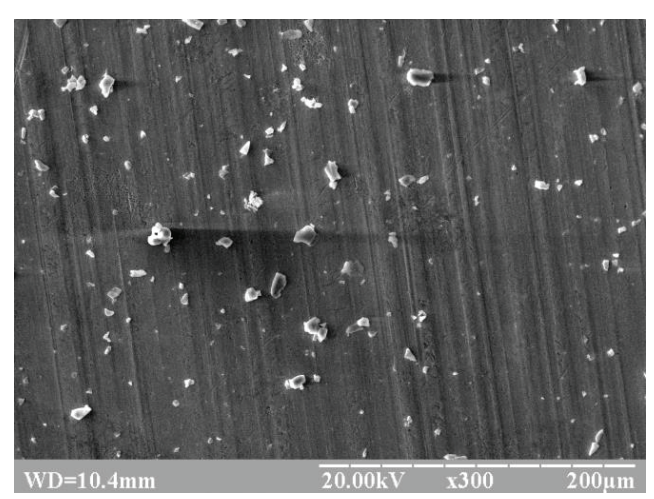

Fig. 6. Microphotography of silicon carbide powder

Silicon carbide powder, synthesized from rice husks, is a polydisperse mixture with particle sizes from one to twenty micrometers. The bulk density of the powder is $215-225 \mathrm{~kg} / \mathrm{m}^{3}$.

\section{2. Calculating the constants of speed and activation} energy of the extraction treatment of rice husks

For the predicted synthesis of silicon carbide of the predefined purity, it is necessary to establish kinetic parameters of the process of extraction treatment of rice husks. Provided that the extraction process obeys pseudo first order, the time dependence of the degree of extraction can be represented by equation:

$$
-\ln (1-\alpha)=k \tau
$$

where $k$ is the constant of speed, $\mathrm{s}^{-1} ; \tau$ is the time of the process.

Graphic dependences that were built from equation (3) for the first section of curves in Fig. 3 are straight lines (Fig. 7). Therefore, the assumption of a pseudo first order of the process of extraction of cellulose from rice husk is adequate to experimental data. The tangent of the slope angle of the lines is equal to the rate constants of the extraction process.
Similar dependences were built for the second section of curves in Fig. 3. Built in the semi-logarithmic coordinates, the dependences are straight lines (Fig. 8) whose tangent of the slope angle is equal to the constants of extraction speed at the appropriate temperature of the process.

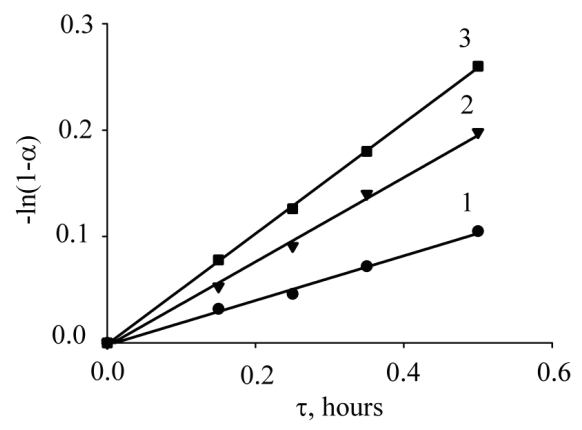

Fig. 7. The first section of the time dependence of the degree of cellulose extraction from rice husk, represented in the semi-logarithmic coordinates, at a temperature of, ${ }^{\circ} \mathrm{C}$ : $1-20 ; 2-40 ; 3-100$

To determine the energy of activation of cellulose extraction from rice husks, we would use the Arrhenius equation:

$$
k=k_{0} \cdot e^{-E / R T},
$$

where $k$ is a constant of speed; $k_{0}$ is the preexponential factor; $E$ is the energy of activation; $R$ is the universal gas constant; $T$ is temperature.

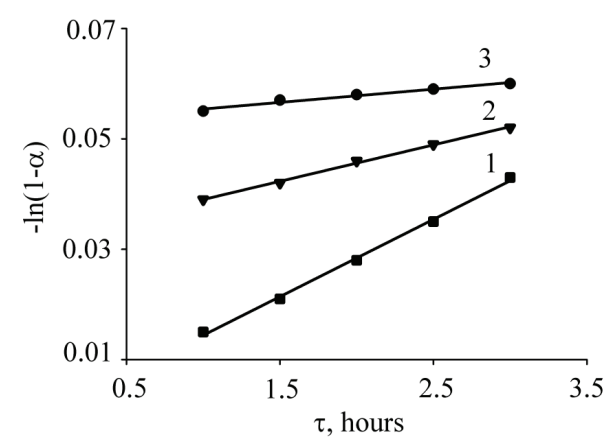

Fig. 8. The second section of the time dependence of the degree of extraction of cellulose from rice husk, represented in the semi-logarithmic coordinates, at a temperature of, ${ }^{\circ} \mathrm{C}$ :

$$
1-20 ; 2-40 ; 3-100
$$

When the logarithm of expression (4) is taken, we derive the dependence in the form $\ln (k)=f(1 / T)$. Energy of the activation process of cellulose extraction from rice husks is found from the tangent of the slope angle of the respective straight lines (Fig. 9).

The calculated kinetic parameters are given in Table 3 .

The resulting values show that the activation energy of the extraction process conducted over a period of 0.5 to 3 hours is larger than twice the energy of the activation of the process in the initial period. This leads to a significant reduction in the extraction rate after 30 minutes of the process. It should be noted that in the first period of the process a rather high degree of extraction is achieved. The increase in temperature to $100{ }^{\circ} \mathrm{C}$ means that the degree of extraction in this period reaches almost the maximum value. 


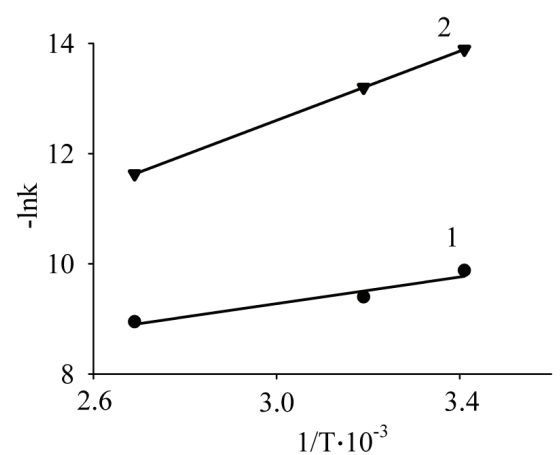

Fig. 9. Dependences of the constant of speed of extraction on temperature in the Arrhenius coordinates, built for: 1 - the first section of curves in Fig. 3; 2 - the second section of the curves in Fig. 3

Table 3

Kinetic parameters of the process of cellulose extraction from rice husks

\begin{tabular}{|c|c|c|c|c|}
\hline \multirow{2}{*}{$\begin{array}{c}\text { Tempera- } \\
\text { ture, }{ }^{\circ} \mathrm{C}\end{array}$} & \multicolumn{2}{|c|}{$\begin{array}{c}\text { First section of time } \\
\text { dependence }\end{array}$} & \multicolumn{2}{|c|}{$\begin{array}{c}\text { Second section of time } \\
\text { dependence }\end{array}$} \\
\cline { 2 - 2 } & $k \cdot 10^{5}, \mathrm{~s}^{-1}$ & $E, \mathrm{~kJ} / \mathrm{mol}$ & $k \cdot 10^{5}, \mathrm{~s}^{-1}$ & $E, \mathrm{~kJ} / \mathrm{mol}$ \\
\hline 20 & 5.12 & & 0.09 & \multirow{2}{*}{26.10} \\
\hline 40 & 8.7 & \multirow{2}{*}{10.75} & 0.19 & \\
\cline { 1 - 2 } & & & 0.89 & \\
\hline 100 & 12.9 & & \multicolumn{2}{|c|}{} \\
\cline { 2 - 2 } & & &
\end{tabular}

\section{Discussion of results of studying the kinetics of the extraction treatment of rice husks when obtaining silicon carbide}

The use of rice husks as raw materials for silicon carbide seems very promising both in terms of rice waste disposal and the possibility of flexible regulation of the parameters of the appropriate technology. It is possible to achieve an increase in the purity of the resulting product by pre-cleaning raw materials from excess carbon.

The choice of an extractant for cleaning rice husks from cellulose showed (Fig. 1) that the optimal extractant for the maximum extraction degree was the extractant consisting of $10 \%$ (by weight) of sulfuric acid and $15 \%$ (by weight) of acetic acid. However, the presence of metal compounds in rice husks makes it difficult to obtain pure silicon carbide, so it is necessary to extract them from the starting raw materials. The use of a mixture of acids as an extractant has made it possible to translate insoluble forms of metal impurities into water-soluble salts and separate them from rice husks. Table 2 demonstrates that the residual content of metals in raw materials is negligibly small. Reports of acid cleaning of rice husk from metal impurities using hydrochloric acid are available in [11]. Removing excess carbon from the starting raw materials by extraction, proposed in the current paper, is innovative.
In order to establish the technological parameters for the extraction cleaning of rice husk from cellulose, empirical evidence on the kinetics of the process is needed. Time dependences of the degree of extraction of cellulose at different temperatures showed (Fig. 2) that the extraction process proceeds at different speeds at the initial moment and after 30 minutes. The calculated speed constants make it possible to predict the timing of extraction at the predefined temperature in order to achieve the required degree of cellulose extraction.

Fig. 4 shows that the stoichiometric ratio of silicon dioxide to carbon (dotted line) in the silicon carbide synthesis reaction (2) is achieved in the course of the extraction process at $100{ }^{\circ} \mathrm{C}$. At the same time, the raw materials prepared in this way before heat treatment did not ensure the complete transformation of silicon dioxide into silicon carbide. The blurred halo of X-ray amorphous phase, which can correspond to amorphous silicon dioxide, indicates that the amount of cellulose extracted as a result of extraction was greater than necessary. Therefore, when obtaining pure silicon carbide from rice husks, depending on the conditions of pyrolysis, the necessary $\mathrm{SiO}_{2}$ :C ratio may differ from the stoichiometric one.

Thus, our experimental data on the kinetics of extractive removal of cellulose from rice husks, and the corresponding speed constants, would make it possible to determine the extraction time with the required degree of extraction under practical technological conditions.

\section{Conclusions}

1. It has been shown that the use of a solution containing $10 \%$ (by weight) of sulphuric acid and $15 \%$ (by weight) of acetic acid as the extractant makes it possible to ensure the cleaning of rice husks from impurities of metal compounds, The proposed extractant provides for the extraction of carbon-containing components up to $25 \%$ of the original sample mass. It has been demonstrated that an increase in the extraction temperature from 20 to $100{ }^{\circ} \mathrm{C}$ results in twice the efficiency of the process. It has been established that the time characteristics of the extraction process have two regions. The first region corresponds to the process time from 0 to 30 minutes. The second extraction region corresponds to the time of the process from 30 minutes to 3 hours.

2. We have established the kinetic parameters of the extraction process, which correspond to two regions of the time dependence. The activation energy of extraction over the first period is $10.75 \mathrm{~kJ} / \mathrm{mol}$; in the second period, the activation energy value is $26.10 \mathrm{~kJ} / \mathrm{mol}$. The speed constant of extraction increases with the increase in temperature. When the temperature increases from 20 to $100^{\circ} \mathrm{C}$, the speed constant increases, in the first period, from $5.12 \cdot 10^{-5}$ to $12.9 \cdot 10^{-5} \mathrm{~s}^{-1}$. In the second period, this change ranges from $0.09 \cdot 10^{-5}$ to $0.89 \cdot 10^{-5} \mathrm{~s}^{-1}$. It has been shown that silicon carbide, synthesized from rice husk after its extraction treatment, is a crystalline material with the size of particles from 1 to 20 micrometers.

1. Neudeck, P. G., Meredith, R. D., Chen, L., Spry, D. J., Nakley, L. M., Hunter, G. W. (2016). Prolonged silicon carbide integrated circuit operation in Venus surface atmospheric conditions. AIP Advances, 6 (12), 125119. doi: https://doi.org/10.1063/1.4973429

2. Ou, H., Ou, Y., Argyraki, A., Schimmel, S., Kaiser, M., Wellmann, P. et. al. (2014). Advances in wide bandgap SiC for optoelectronics. The European Physical Journal B, 87 (3). doi: https://doi.org/10.1140/epjb/e2014-41100-0 
3. Anisimov, A. N., Simin, D., Soltamov, V. A., Lebedev, S. P., Baranov, P. G., Astakhov, G. V., Dyakonov, V. (2016). Optical thermometry based on level anticrossing in silicon carbide. Scientific Reports, 6 (1). doi: https://doi.org/10.1038/srep33301

4. Chen, D., Wong, S. P., Yang, S., Mo, D. (2003). Composition, structure and optical properties of SiC buried layer formed by high dose carbon implantation into Si using metal vapor vacuum arc ion source. Thin Solid Films, 426 (1-2), 1-7. doi: https://doi.org/ 10.1016/s0040-6090(02)01298-1

5. Tablero, C. (2013). Optoelectronic Application of the 3C-Silicon Carbide with Substitutional VIII-Group Atoms. The Journal of Physical Chemistry C, 117 (42), 21949-21954. doi: https://doi.org/10.1021/jp4074015

6. Xu, C., Xu, C., Han, F., Zhang, F., Wei, W., Zhong, Z., Xing, W. (2018). Fabrication of high performance macroporous tubular silicon carbide gas filters by extrusion method. Ceramics International, 44 (15), 17792-17799. doi: https://doi.org/10.1016/ j.ceramint.2018.06.247

7. D'Elia, R., Bernhart, G., Hijlkema, J., Cutard, T. (2016). Experimental analysis of SiC-based refractory concrete in hybrid rocket nozzles. Acta Astronautica, 126, 168-177. doi: https://doi.org/10.1016/j.actaastro.2016.04.034

8. Saddow, S. E. (2012). Silicon Carbide Biotechnology: A Biocompatible Semiconductor for Advanced Biomedical Devices and Applications. Elsevier, 495. doi: https://doi.org/10.1016/c2010-0-67866-7

9. Malanchuk, V., Astapenko, E., Chepurnoii, Y., Zhukovtceva, E. (2013). Experimental research into the uses of new composite materials in maxillofacial surgery. Sovremennaya meditsina: Aktual'nye voprosy, 23, 92-102.

10. Matizamhuka, W. R. (2019). Gas transport mechanisms and the behaviour of impurities in the Acheson furnace for the production of silicon carbide. Heliyon, 5 (4), e01535. doi: https://doi.org/10.1016/j.heliyon.2019.e01535

11. Makornpan, C., Mongkolkachit, C., Wanakitti, S., Wasanapiarnpong, T. (2014). Fabrication of Silicon Carbide from Rice Husk by Carbothermal-Reduction and In Situ Reaction Bonding Technique. Key Engineering Materials, 608, 235-240. doi: https://doi.org/ 10.4028/www.scientific.net/kem.608.235

12. Shariatmadar Tehrani, F., Fakhredin, M., Tafreshi, M. J. (2019). The optical properties of silicon carbide thin films prepared by HWCVD from pure silane and methane under various total gas partial pressure. Materials Research Express, 6 (8), 086469. doi: https://doi.org/10.1088/2053-1591/ab2843

13. Ezdin, B. S., Yatsenko, D. A., Kalyada, V. V., Ichshenko, A. B., Zarvin, A. E., Nikiforov, A. A., Snytnikov, P. V. (2020). Pyrolysis of a mixture of monosilane and alkanes in a compression reactor to produce nanodispersed silicon carbide. Chemical Engineering Journal, 381, 122642. doi: https://doi.org/10.1016/j.cej.2019.122642

14. Silicon Carbide: Synthesis and Properties (2011). InTech. doi: https://doi.org/10.5772/15736

15. Rodriguez-Lugo, V., Rubio, E., Gomez, I., Torres-Martinez, L., Castano, V. M. (2002). Synthesis of silicon carbide from rice husk. International Journal of Environment and Pollution, 18 (4), 378. doi: https://doi.org/10.1504/ijep.2002.003734

16. Ahmad, K. (2014). Optimising the Yield of Silicon Carbide Synthesised from Indigenous Biomass Husk using Different Catalysts. Journal of Material Science \& Engineering, 03 (03). doi: https://doi.org/10.4172/2169-0022.1000147

17. Johar, N., Ahmad, I., Dufresne, A. (2012). Extraction, preparation and characterization of cellulose fibres and nanocrystals from rice husk. Industrial Crops and Products, 37 (1), 93-99. doi: https://doi.org/10.1016/j.indcrop.2011.12.016

18. Rosa, S. M. L., Rehman, N., de Miranda, M. I. G., Nachtigall, S. M. B., Bica, C. I. D. (2012). Chlorine-free extraction of cellulose from rice husk and whisker isolation. Carbohydrate Polymers, 87 (2), 1131-1138. doi: https://doi.org/10.1016/j.carbpol.2011.08.084

19. Shukla, S. K., Sagar, Naman, Deepika, Sundaram, Prateeksha et. al. (2015). Extraction of Cellulose Micro Sheets from Rice Husk: A Scalable Chemical Approach. DU Journal of Undergraduate Research and Innovation, 1 (3), 187-194.

20. Oliveira, J. P. de, Bruni, G. P., Lima, K. O., Halal, S. L. M. E., Rosa, G. S. da, Dias, A. R. G., Zavareze, E. da R. (2017). Cellulose fibers extracted from rice and oat husks and their application in hydrogel. Food Chemistry, 221, 153-160. doi: https://doi.org/10.1016/ j.foodchem.2016.10.048

21. Kalapathy, U. (2000). A simple method for production of pure silica from rice hull ash. Bioresource Technology, 73 (3), $257-262$. doi: https://doi.org/10.1016/s0960-8524(99)00127-3

22. Nikitin, V. M., Obolenskaya, A. V., Shchegolev, V. P. (1978). Himiya drevesiny i tsellyulozy. Moscow: Lesnaya promyshlennost', 368.

23. Gridneva, T., Kravchenko, A., Barsky, V., Gurevina, N. (2016). Obtaining of High Purity Amorphous Silicon Dioxide from Rice Husk. Chemistry \& Chemical Technology, 10 (4), 499-505. doi: https://doi.org/10.23939/chcht10.04.499 